\title{
A Corpus-based Investigation of Diachronic Evolution of Like and Its Variants through Grammaticalization
}

Qing Liang Meng*

${ }^{1}$ Foreign Languages School, College of Applied Technology, Jiaxing University, China

${ }^{2}$ School of Languages, Cultures and Linguistics, University College Dublin, Dublin 14, Dublin, Ireland

Corresponding Author: Qing Liang Meng, E-mail: qing.meng@ucdconnect.ie

\section{ARTICLE INFO}

Article history

Received: February 08, 2019

Accepted: May 18, 2019

Published: June 30, 2019

Volume: 10 Issue: 3

Advance access: May 2019

Conflicts of interest: None

Funding: None

\begin{abstract}
The purpose of this research is to investigate the diachronic evolution of the word "like" and its variants "likely", "like to", "feel like", and "would like to", etc. in the process of grammaticalization. Statistics from the search of corpora BNC and COHA show the variants of "like" and their historical trend of grammatication. The results demonstrate the highly active role of "like" in both lexical and grammatical functions in history. Furthermore, the variants and collocations of "like" have been the result of frequent interaction between human beings and languages. The findings have significant implications for second language pedagogy.
\end{abstract}

Key words:

Corpora,

Grammaticalization,

Like,

Variant,

Diachronic Evolution,

Second Language Pedagogy

\section{INTRODUCTION}

As a tool of human beings for communication, languages are in a state of constant change and evolution. Such changes and evolution of languages are believed to be the result of interaction among community members and between human beings and the environment in daily activities. In the process of communication, each language has developed its own vocabulary, grammar and syntactic structures, which have not only formed the cognitive style of the people speaking this language but have also been influenced more or less by communication. The unique characteristics of one language have given rise to difficulties for learners of this language speaking another language, such as the case of Chinese learners of English as a second language. One typical difficulty encountered frequently by L2 learners of English in classroom environment in China is the acquisition and use of the word "like".

With the frequency of 1064 per million words in the British National Corpus (BNC), "like" is highly active with strong collocational ability. Many students at university level have difficulty telling the meaning of "What is he like?" apart from "What does he like?", or sometimes they are not sure about the parts following "feel like", "likely" or "like".
One reason for such difficulties may lie in the fact that, as an active word with high frequency, "like" had experienced diachronic evolution over the long history and has thus assumed varied forms, richer content and more grammatical functions. To put it simply, the word "like" has been grammaticalized. Therefore, an investigation into the process of grammaticalization of "like" is expected to shed some light on the understanding and usage of the word and its variants. However, rare research is found in current literature concerning the diachronic evolution of "like" and its variants through grammaticalization. This research is an attempt to provide a comprehensive overview of "like" and some practical advice for the teaching and acquisition of the word and its variants.

\section{LITERATURE REVIEW}

\section{Grammaticalization}

Grammaticalization has been generally considered to be the major means by which language changes over time. The term "grammaticalization" is believed to be coined by the French linguist Antoine Meillet in 1912. Hopper \& Traugott (1993) pointed out that, Meillet's ideas on the origins 
of grammatical forms can be further traced back to German philosopher and humanist Wilhelm von Humboldt (17671835) who, as early as 1822 , had suggested that "the grammatical structure of human languages was preceded by an evolutionary stage of language in which only concrete ideas could be expressed", and grammar "evolved through distinct stages out of the collocation of concrete ideas" (Humboldt 1825, quoted from Hopper \& Traugott 1993: 18). It is based on such previous theories that Hopper \& Traugott defined grammaticalization as "the process whereby lexical items and constructions come in certain linguistic contexts to serve grammatical functions, and, once grammaticalized, continue to develop new grammatical functions. It is the process whereby the properties that distinguish sentences from vocabulary come into being diachronically or are organized synchronically (Hopper \& Traugott 1993: xv)". As a framework to account for language phenomenon, grammaticalization refers to language study focusing on the ways in which grammatical forms and constructions are formed and used, and also to the way of how a language is shaped. From historical perspective, grammaticalization is "usually thought of as that subset of linguistic changes through which a lexical item becomes more grammatical", while from synchronic perspective, it is primarily seen as "a syntactic, discourse pragmatic phenomenon, to be studied from the point of view of fluid patterns of language use" (ibid.). Based on such a definition of Hopper \& Traugott, the examples of grammaticalization have two characteristics in common: (a) Earlier forms may coexist with later ones (i.e. go, let, be); (b) Earlier meanings may constrain later meanings and/or structural characteristics.

Heine defines grammaticalization as "a process whereby a linguistic expression $\mathrm{E}$, in addition to its conventional meaning $M 1$, receives a more abstract and more grammatical meaning $M 2$. With $M 1$ we refer to the meaning of the source schemas,... and with $M 2$ to the possessive meanings these source schemas acquire" (Heine 1997:76). In line with this definition, he further illustrates that the process of grammaticalization has both cognitive and pragmatic components, with the former being described with reference to metaphorical extension while the latter having to do with context manipulation(ibid.). Roberts \& Roussou studied grammaticalization from a minimalist approach, contending that the content of at least one functional category will be reanalyzed in the process of grammaticalization. In this way, "new morphophonological realizations of functional features are created", the result of which is the reanalysis of a lexical item or class of lexical items as "functional", or the development of one functional category into another (Roberts \& Roussou 2003: 35). From the 1980s to early 2000s, research on grammaticalization "has established itself as a major area in linguistic studies" (Lindquist \& Mair 2004). Diessel (2011) made a comparison between the diachronic evolution of grammatical markers and their development in child language, finding that grammaticalization and first language acquisition involve the same semantic changes quite often. Further investigation revealed the trend of development from "more concrete meanings" to "abstract grammatical meanings”. More recently, Bichakjian (2017) summarized language evolution brought about by grammaticalization into five categories, including (1) the coinage of nouns and verbs; (2) the coinage of adjectives; (3) the making of grammatical markers; (4) from aspect to tense; and (5) syntactic changes. A few key terms of grammaticalization might help us with a better understanding of grammaticalization. A few key terms of grammaticalization are illustrated in the following sections.

\section{Cline}

"Cline" is a basic term in grammaticalzation, and it is the "progression from lexical noun, to relational phrase, to adverb and preposition, and perhaps even to a case affix" (Hopper \& Traugott 1993: 6). According to Hopper \& Traugott, instead of changing abruptly, a cline will go through a series of natural and gradual transitions from one category to another, just like a kind of linguistic "slippery slope" guiding the development of form. And this is the cline observed from historical perspective. From synchronic point of view, a cline is compared to a "continuum" in which forms are arranged along "an imaginary line", with lexical form at one end and grammatical form at the other end. Take the word "back" for example. At one end, it is a lexical noun, meaning a part of a body in the sentence: He is carrying a heavy bag on his back; while at the other end, its grammatical function is adverbial, as in: You'd better come back for dinner. The word back also functions as an adjective and verb, which are on the line of gradual change.

\section{Reanalysis and Analogy}

Reanalysis and analogy are considered by Hopper \& Traugott (1993) to be the mechanisms of grammaticalization, and have been "widely recognized as significant for change in general, most especially morphosyntactic change" (Hopper \& Traugott 1993: 32). Reanalysis, as defined by Langacker (1977), is "change in the structure of an expression or class of expression that does not involve any immediate or intrinsic modification of its surface manifestation" (Langacker 1977:58). According to Hopper \& Traugott (1993), reanalysis modifies underlying representations and make changes to rules. Lehmann (2004) posits that the reanalysis of a construction is "the assignment of a different grammatical structure to it", and concludes based on the analysis of some examples that reanalysis "may occur as a component of a grammaticalization process" (Lehmann 2004).

As a major factor in language change, reanalysis can sometimes result in changes with grammatical effects, but nevertheless involving a shift "from grammatical to lexical structure, rather than from lexical to grammatical structure"(Hopper \& Traugott 1993: 48). One such example is a non-lexical form of up which becomes a fully referential lexical item. When reanalysis is generally referred to as the process of new forms growing out of old structures, analogy is regarded as "the attraction of extant forms to already existing constructions" (Hopper \& Traugott 1993: 56). Lehmann (2004) maintains that analogical grammatical change and grammaticalizaiton "are distinct and may even be disjunct in particular cases" and 
thus distinguishes two kind of historical changes, one being pure grammaticalization without involvement of analogical model, such as the numeral 'one' to an indefinite article; the other being the cases in which an analogical model is needed to motivate particular course of grammaticalization. Hopper \& Traugott summarized that reanalysis and analogy have different effects, with the former "essentially involves linear, syntagmatic, often local, reorganization and rule change" while the latter "essentially involves paradigmatic organization, change in surface collocations, and in patterns of use" (ibid:61). The following diagram shows the differences between reanalysis and analogy in the grammaticalizaiton of "be going to": See Figure 1 below.

\section{Unidirectionality}

From diachronic perspective, grammaticalization is "hypothesized to be prototypically a unidirectional phenomenon" (Hopper \& Traugott 1993: 94). As explained by Hopper \& Traugott, unidirectionality in the process of grammaticalization means that, the lexical items must first serve commonly needed discourse function before being grammaticalized. Then they become syntactically fixed and eventually amalgamate morphologically as stem and affix. Several typical processes will lead to semantic and/or structural generalization and decategorization, including specialization (e.g. Il ne boit pas de vin) divergence (Would you like $\boldsymbol{a}$ Mai Tai?), and renewal (as very alternates with most, surprisingly, high$\boldsymbol{l} \boldsymbol{y}$, etc.). However, even though there is extensive evidence of unidirectionality, it is by no means an absolute principle, "Some counterexamples do exist" (Hopper \& Traugott 1993: 126). Lehmann has the same point of view in this aspect, suggesting that "Grammaticalization is unidirectional in the sense that changes that go in the opposite direction of grammaticalization are observed very rarely" and "a process leading from the end point to the starting point of grammaticalization does not exist"(Lehmann 2004).

Of course, there are a lot of other terms in grammaticalization, which are based on the above three terms and constitute an extension in the research of this language phenomenon but will not be touched upon here. A few examples will be presented in the following section and will be

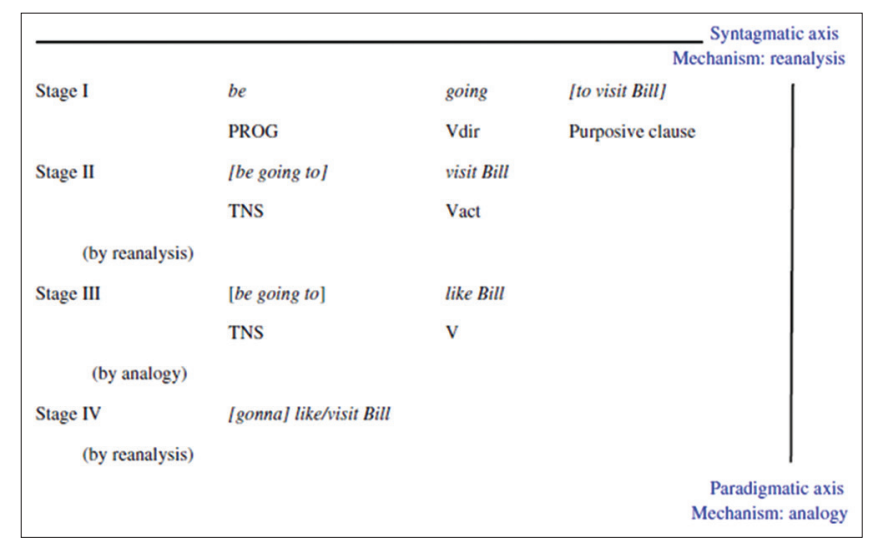

Figure 1. Schema for the development of auxiliary be going to by Hopper and Traugott

(Source: Hopper \& Traugott 1993: 61) studied using corpus linguistic approach to show the process of grammaticalization from both diachronic and synchronic perspectives.

\section{Meehan's Research on "like"}

Meehan (1991) is one of the very few researchers who had explored the grammaticalization path of the word "like" from a historical point of view. She found several meanings associated with "like" in standard American English and the earliest one can be traced back to the $14^{\text {th }}$ century in the Old English Dictionary. By demonstrating the fact that the changes of syntactic constituents are accompanied by changes in the meaning of "like", she argued that a new meaning of "like" usually derives from an older meaning which is "becoming more generalized" in the process of grammaticalization (Meehan 1991:38). The various meaning of "like" in different periods in history are summarized in the following table (Adapted from Meehan 1991:49).

\begin{tabular}{lcl}
\hline Meaning & $\begin{array}{l}\text { Earliest } \\
\text { Documentation }\end{array}$ & Present-day Scope \\
\hline $\begin{array}{l}\text { Similar to } \\
\text { As if }\end{array}$ & 1300 & $\begin{array}{l}\text { (post-verbal) NP } \\
\text { (post-verbal or clause) } \\
\text { Clause }\end{array}$ \\
Approximately & 1386 & NP (Quant.) \\
For example & 1886 & NP, PP Clause \\
$\begin{array}{l}\text { No lexical } \\
\text { meaning (below) }\end{array}$ & & \\
Focus like & 1959 & NP, VP, ADJ., Clause \\
Quote like & $1960+$ & Clause \\
\hline
\end{tabular}

Meehan (1991) provided examples of sentences containing the different meanings of "like" respectively.

(a1) "similar to": She sings like her, laughs like her, talks like her (MADAME D’ARBLAY (1779) Diary \& Letters).

(a2) "as if": Like you could afford the house I want.

(a3) "approximately": I wanted it like this short.

(a4) "for example": Do you have like a mint or something?

According to Meehan (1991), from the sense of "similar to" to "for example", the scope is becoming broader and broader. Then, with lexical meanings being bleached out, the word "like" could be removed in some cases, while "the overall semantics of the utterance" remain unchanged, as in the following two sentences:

(b1) I had to wash my hair because it was like gross.

(b2) I think he is like borderline.

In the two examples above, the word "like" mainly functions to raise the listeners' attention. With the meaning of "like" becoming more and more generalized, it assumes more grammatical than lexical function, as in the following two examples:

(c1) She's like really pregnant. (Focus)

(c2) It's like "How am I supposed to know"? (Quote)

Thus, the usage of "like" is moving from the left (more lexical) to the right (more grammatical) within the functional continuum.

Therefore, Meehan (1991) presented a general glimpse of the diachronic change of the word "like" based on its 
path of grammaticalization, which clearly demonstrated the process of evolution from a more lexical into a more grammatical item. However, a more comprehensive investigation of the usage of "like" is expected to be of significance for second language pedagogy. With the aid of corpora BNC and COHA, we'd like to show the diachronic evolution of "like" and its variants in the hope of helping address one difficulty of vocabulary acquisition frequently encountered by L2 learners of English.

\section{METHODOLOGY}

\section{Corpora}

The word "like" is highly frequently used in both written and spoken English and is a very active word. Generally words like "like" must have gone through a process of deep grammaticalization during which it has assumed more grammatical functions and extended its lexical meaning. So it would be interesting to have a look at its grammaticalization process.

In this research, British National Corpus (BNC) will be used because (a) it is a free online corpus with easy access; (b) it is a general corpus and the study of grammaticalizaiton of "like" is not necessarily confined to any specific domain; (c) it has a 100-million-word collection of samples of a written and spoken language of British English from the later part of the $20^{\text {th }}$ century; (d) it consists of the bigger written part $(90 \%$, e.g. newspapers, academic books, letters, essays, etc.) and the smaller spoken part (remaining $10 \%$, e.g. informal conversations, radio shows, etc.) See Figure 2 for a general description of BNC.

Since grammatical changes would usually take centuries to achieve the current functions, it is better to observe their evolution from historical perspective, therefore, Corpus of Historical American English (COHA) will also be used to elicit relevant data. As the largest structured corpus of historical English, COHA covers a span of 200 years from 1810s to 2000 s and is composed of twenty sub-corpora by decades with balanced genres covering fiction, magazine, newspaper and non-fiction.

The use of both BNC and COHA will enable us to examine the occurrences of "like" and its variants from both diachronic and synchronic perspectives.

\section{Data Collection}

SketchEngine was used for searching and making basic analysis. As a powerful corpus manager and text analysis software, it is developed by Lexical Computing Limited and can enable us to study language behavior to search large text collections according to complex and linguistically motivated queries. It contains hundreds of corpora in different languages, and more than sixty of them are in English. With the registered ID of the University College Dublin, we are able to access most of its corpora and make use of the functions. We first used the "Word Sketch" function, confined to BNC, and got the following information:

\begin{tabular}{lc}
\hline Item & Proportion \\
\hline Modifiers of like & 22.18 \\
Objects of like & 21.46 \\
Subjects of like & 11.50 \\
Like and/or... & 1.41 \\
Prepositional phrases & - \\
Particles after like with object & 0.10 \\
Pronominal objects of like & 14.21 \\
Pronominal subjects of like & 37.27 \\
Wh-words following like & 0.81 \\
Infinitive objects of like & 31.23 \\
-ing objects of like & 2.08 \\
Adjectives after like and noun & 0.60 \\
Adjectives after like & 0.51 \\
Usage patterns & - \\
\hline
\end{tabular}

From the above table, we know that "like" is very active, serving as adjective, preposition, adverb, conjunction, noun and verb, meaning "having the same characteristics or qualities as", "drawing attention to the nature of an action or event", or "such as; for example; approximately", etc.

With time going on, the word "like" has experienced the process of grammaticalization, either in combination with other suffixes to constitute single words, or forming set phrases with fixed lexical meaning, or assuming more grammatical functions with less lexical meaning. By searching $\mathrm{COHA}$, we obtained the frequency of these new words and phrases based on "like", including "likes (noun)", "liking", "likely", "feel like", "like to", "would like to" from 1810s to 2000s. (See Figure 3)

The change of use frequency of "like" and its variants are shown in the following figure (Figure 3).

\begin{tabular}{|c|c|c|c|c|c|c|c|c|c|}
\hline \multicolumn{10}{|c|}{ British National Corpus (BNC) 8} \\
\hline \multicolumn{10}{|c|}{ Balanced English corpus of written and spoken language. Processed by TreeTagger pipeline v2.1 } \\
\hline \multicolumn{2}{|l|}{ Counts } & \multicolumn{2}{|l|}{ General info } & \multicolumn{2}{|c|}{ Lexicon sizes } & \multicolumn{2}{|l|}{ Tags legend } & \multicolumn{2}{|c|}{ Lempos suffixes } \\
\hline Tokens & $112,345,722$ & Corpus description & Document & word & 724,893 & adjective & J.* & adjective & $-j$ \\
\hline Words & $96,134,547$ & Language & English & tag & 64 & adverb & RB.? & adverb & -a \\
\hline Sentences & $6,052,190$ & Encoding & UTF-8 & lempos & 589,534 & conjunction & CC & conjunction & $-c$ \\
\hline Paragraphs & $1, \mathbf{5 1 4 , 9 0 6}$ & Compiled & $03 / 26 / 2018$ 12:27:55 & lempos_lc 8 & 524,493 & determiner & DT & noun & $-n$ \\
\hline \multirow[t]{5}{*}{ Documents } & 4,054 & Tagset & Description & lemma & 556,241 & noun & N.* & preposition & $-i$ \\
\hline & & Word sketch grammar & Definition & lc 0 & 600,533 & noun singular & NN & pronoun & - \\
\hline & & & & lemma_lc $\theta$ & 484,374 & noun plural & NNS & verb & $\cdot \mathrm{v}$ \\
\hline & & & & & & numeral & $C D$ & & \\
\hline & & & & & & Darticle & RP & & \\
\hline
\end{tabular}

Figure 2. Description of BNC 
From the above figure we see that, the use of "like" has been increasing steadily since 1810 , especially from the 1980 s to the 1990 , during which there was a sharp increase.

Some concordances of "like" are randomly chosen from COHA:

Two examples of the use of like from COHA:

(1) There motionless I stood alone, like some strange monument of stone Upon a barren wild; (1813, The Sylphs of the Seasons with other poems, by Washington Allston 1779-1843. COHA-1)

(2) Your past experiences may make you want your family to not be such a powerful influence on who you are or who you become, but it is, whether you like it or not. (2004, Family first: your step-by-step plan for creating a phenomenal family, by Phillip C. McGraw, 1950. COHA-70109)

Here, "like" in example (1) serves as a preposition, meaning "similar to; in the same way or manner as"; in example (2), "like" serves as a verb, meaning "to enjoy or approve of something or someone". These are the basic grammatical functions of the word "like" and its lexical meanings.

However, due to the large number of occurrences of "like", the change pattern of its variants is not demonstrated clearly in the above Figure 3, so another figure (Figure 4) without "like" was used to show the historical trend of change of its variants.

It can be seen from this figure that, the use frequency of most of these words and phrases has been experiencing a steady increase during this period, with the exception of "liking", which, after reaching a high point in the 1920s, has been decreasing ever since. A few concordances of "liking", "likely", "feel like" are listed in the following:

(3) But as I was saying sir, I want not gold, I only wish a service to my liking until such time as my old lord and I shall agree to come together again Twill not be long. (1810, The Italian Father, by William Dunlap. COHA-1)

(4) In Danto's frame, an African liking for images of a certain type can only be explained by exposure to other images, a process of visual enculturation. (2009, The art instinct: beauty, pleasure, \& human evolution, Denis Dutton, New York: Bloomsbury Press,Edition: $1^{\text {st }}$ U.S. ed. COHA-3478)

(5) The philosophers were, therefore, the most likely to assist the artist in those displays of character which tended to illustrate the truth of his own works. (1816, The Life, Studies, and Works of Benjamin West, Esq.: Composed

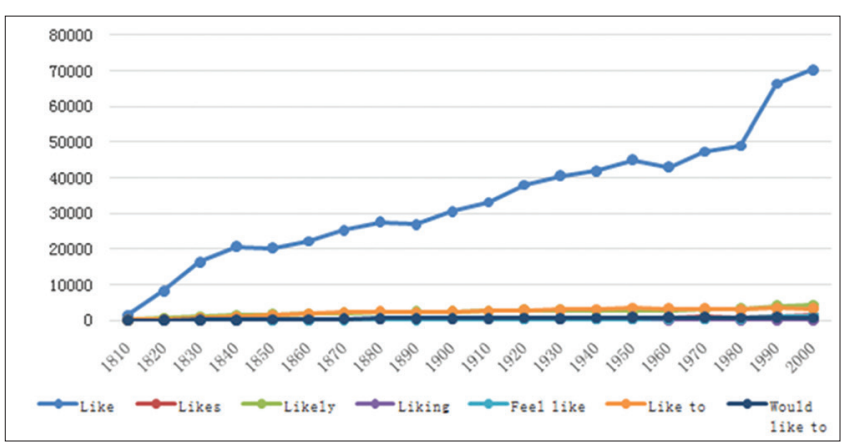

Figure 3. The historical trend of the usage of "like" and its variants in $\mathrm{COHA}$

\begin{tabular}{|c|c|c|c|c|c|c|c|c|c|c|c|c|c|c|c|c|c|c|c|c|}
\hline Year & 1810 & 1820 & 1830 & 1840 & 1850 & 1860 & 1870 & 1880 & 1890 & 1900 & 1910 & 1920 & 1930 & 1940 & 1950 & 1960 & 1970 & 1980 & 1990 & 2000 \\
\hline Like & $\underline{1501}$ & $\underline{8281}$ & $\underline{16350}$ & $\underline{20650}$ & $\underline{20201}$ & $\underline{22142}$ & 25321 & $\underline{27515}$ & $\underline{26835}$ & 30598 & 33161 & $\underline{38013}$ & 40496 & 41928 & 44984 & $\underline{42997}$ & 47360 & 49005 & 66334 & $\underline{70295}$ \\
\hline Likes & $\underline{6}$ & $\underline{35}$ & $\underline{131}$ & $\underline{129}$ & $\underline{203}$ & $\underline{\underline{265}}$ & $\underline{406}$ & $\underline{405}$ & $\underline{354}$ & $\underline{424}$ & $\underline{487}$ & $\underline{696}$ & $\underline{631}$ & $\underline{709}$ & $\underline{818}$ & $\underline{787}$ & $\underline{854}$ & $\underline{836}$ & $\underline{1208}$ & 1301 \\
\hline Likely & $\underline{150}$ & $\underline{629}$ & $\underline{1120}$ & $\underline{1339}$ & $\underline{1605}$ & $\underline{1686}$ & $\underline{2067}$ & $\underline{2313}$ & $\underline{2405}$ & $\underline{2401}$ & $\underline{2524}$ & $\underline{2806}$ & $\underline{2771}$ & $\underline{2652}$ & $\underline{2596}$ & $\underline{2655}$ & $\underline{\underline{2923}}$ & $\underline{3191}$ & $\underline{3986}$ & $\underline{4358}$ \\
\hline Liking & $\underline{3}$ & $\underline{22}$ & $\underline{123}$ & $\underline{104}$ & $\underline{153}$ & $\underline{162}$ & $\underline{213}$ & $\underline{257}$ & $\underline{214}$ & $\underline{262}$ & $\underline{244}$ & $\underline{272}$ & $\underline{217}$ & $\underline{217}$ & $\underline{186}$ & $\underline{157}$ & $\underline{204}$ & $\underline{164}$ & $\underline{139}$ & $\underline{165}$ \\
\hline Feel like & $\underline{2}$ & $\underline{12}$ & $\underline{21}$ & $\underline{42}$ & $\underline{90}$ & $\underline{105}$ & $\underline{154}$ & $\underline{186}$ & $\underline{141}$ & $\underline{256}$ & $\underline{\underline{308}}$ & $\underline{\underline{315}}$ & $\underline{\underline{356}}$ & $\underline{\underline{399}}$ & $\underline{420}$ & $\underline{453}$ & $\underline{563}$ & $\underline{533}$ & $\underline{\underline{993}}$ & $\underline{1185}$ \\
\hline Like to & $\underline{42}$ & $\underline{282}$ & $\underline{708}$ & 934 & 1482 & $\underline{1707}$ & $\underline{2126}$ & $\underline{2407}$ & $\underline{2198}$ & $\underline{2347}$ & $\underline{2570}$ & $\underline{2839}$ & $\underline{2913}$ & 3143 & $\underline{3430}$ & $\underline{3279}$ & $\underline{3274}$ & $\underline{\underline{2990}}$ & $\underline{3388}$ & $\underline{3241}$ \\
\hline $\begin{array}{l}\text { Would } \\
\text { like to }\end{array}$ & $\underline{3}$ & $\underline{19}$ & 55 & 9 & $\underline{249}$ & 297 & $\underline{413}$ & $\underline{516}$ & $\underline{458}$ & 477 & $\underline{471}$ & $\underline{\underline{n}}$ & 55 & $\underline{641}$ & $\underline{773}$ & $\underline{763}$ & 78 & $\underline{707}$ & $\underline{730}$ & $\underline{617}$ \\
\hline
\end{tabular}

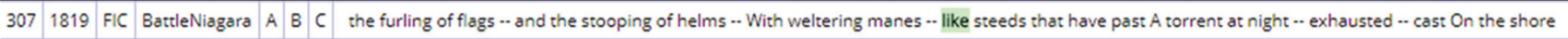
3081819 FIC BattleNiagara A B C loosen to the wind his crimson streaming mane! 0 , there's no mockery like the morning light, Smiling o'er relicks of a bloody night; Like a red 3091819 FIC BattleNiagara A B C C no mockery like the morning light, Smiling o'er relicks of a bloody night; Like a red lustre on a barren mount: Like the rich moon-beam o'er a silent 3101819 FIC BattleNiagara A B C relicks of a bloody night; Like a red lustre on a barren mount: Like the rich moon-beam o'er a silent fount, Swimming in feverish splendour, while it 3111819 FIC BattleNiagara A B C C war; Wake thy swift bugle, let it sing away Freshly and clear, like clarion of the day! Loosen thy banners on the mountain winds! Call up 3121819 FIC BattleNiagara A B C for thee? -- when blade met blade; And man met man, and like the desert beast, That bleeds and battles' till his breath has ceased; \begin{tabular}{l|l|l|l|l|l|l|l}
99996 & 1878 & FIC & [PoemsIn]AMasque & A & B & C & us, And not the overpowering and tremendous! While love, debased, is like the prophet's rod, Which changed into a serpent on the ground, Exalted
\end{tabular} 999971878 FIC [PoemsIn]AMasque A A B C husband's, come to me! "She wrote, - or words of like portentous presage; And off went Lorne, obedient to the message. VII. 999981878 FIC [PoemsIn]AMasque $A$ A C hope That ever he can get on Saturn's trace: And how can one like him expect to cope With a great villain of such crafty ways? Still,

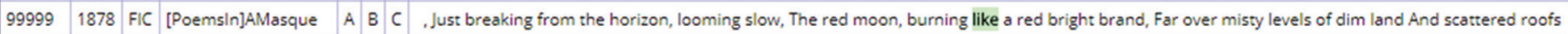
1000001878 FIC [PoemsIn]AMasque A A B C and studies day and night, And tries experiments, until he looks Dazed, like an owl that' s brought too near the light: Keeps that black coachman \begin{tabular}{l|l|l|l|l|l|l|l}
70283 & 2003 & NF & RightManSurprise & A & B & C & groups claimed to be highly impressed by him, on television he did not look like a man ready to be president. The late-night comedians and Bush's D \\
\hline
\end{tabular} \begin{tabular}{|l|l|l|l|l|l}
70284 & 2003 & NF & RightManSurprise & A B & .// Bush described himself as a " compassionate conservative, "which sounded less like a philosophy than a marketing slogan: Love conservatism bu
\end{tabular}

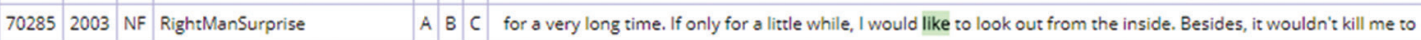
702862003 NF Negropresident $\quad$ A B C who were not southerners had to temporize with the South. // Northerners or westerners like Van Buren, Tyler, Polk, Clay, and Buchanan // helped al

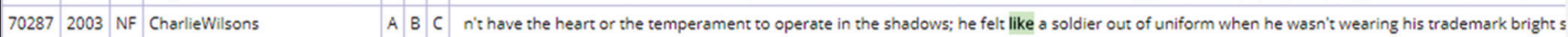

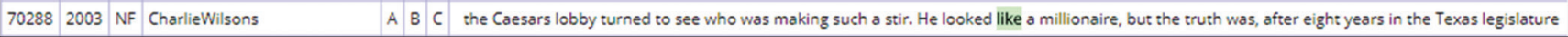


from Materials Furnished by Himself, by John Galt, Philadelphia: Moses Thomas. J. Maxwell. COHA-26)

(6) I am sure the time will come when nobody can make Charles feel like blushing for me; (1837, Live and Let Live; or, Domestic Service Illustrated, by Sedgwick, Catharine Maria, 1789-1867. COHA-27)

(7) The important thing to me about this new book was the recipe selections. I didn't want ya'll to feel like you were seeing recipes that you had seen over and over and over again. (2006, Paula Deen celebrates!: best dishes and best wishes for the best times of your life, by Paula H. Deen, 1947- Nesbit, Martha Giddens. New York: Simon \& Schuster. COHA-6528)

(8) Think you folks would like to stop and try a ride on the merry-go-round? " Calibree considered it, (1920, Main Street, by Sinclair Lewis, 1885-1951. COHA-5)

\section{Discussion}

As we know, grammaticalization is a gradual process involving both semantic and structural changes. During this process, constructions of particular lexical items are used with increasing frequency and gradually become new grammatical constructions (Bybee, Perkins, and Pagliuca 1994; Givón 1979; Heine and Kuteva 2002; Traugott 2003, quoted from Narrog \& Heine 2011). The concordances of the word "like" in COHA clearly show that the use frequency has been on the rise from 1810s to the 2000s. During the initial period, it mainly served as a verb and preposition. Through grammaticalization, "like" had assumed more grammatical functions and lexical meanings. As pointed out above by Hopper \& Traugott (1993), reanalysis and analogy are the mechanisms of grammaticalization, and "[O]ne of the simplest types of reanalysis, and one very frequently found in grammaticalization, is fusion: the merger of two or more forms across word or morphological boundaries" (Hopper \& Traugott 1993: 40). In the evolution of languages, many highly productive derivational affixes, such as -hood, -dom, -ly, etc. were compounded with other nouns, and here, the words "liking", "likely" were formed in this way, assuming new lexical meanings overlapping with the original meaning of "like". However, from Figure 4 above, we know that the two variants of "like" enjoy different fate of popularity. "Liking", which means "favorable regard", has been decreasing in terms of use frequency since the 1920s. Whereas "likely", after experiencing a period of decrease from the 1920 s to the 1950 s, gained its

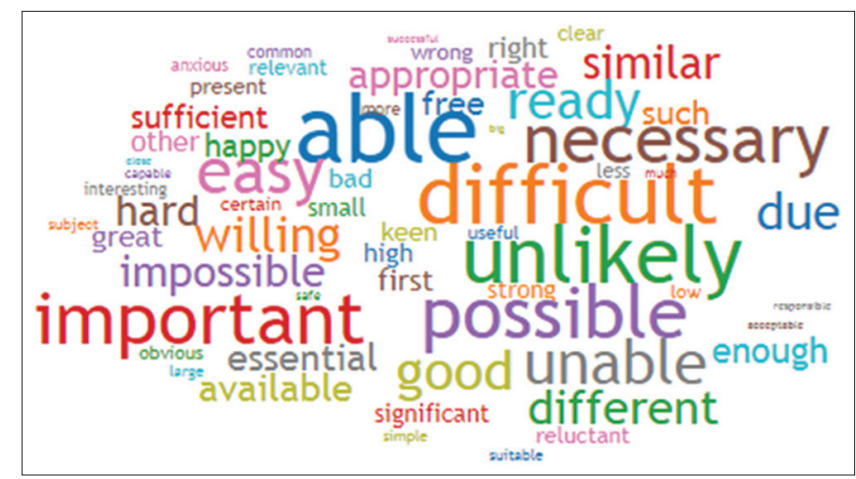

Figure 4. Thesaurus of "likely" in BNC through Sketch Engine momentum in the 1950s and has been on a sharp rise ever since. The thesaurus of "likely" in BNC through Sketch Engine (Figure 4) is shown in the following schema:

An interesting phenomenon as shown in Figure 5 is that, the period during which "likely" gained its momentum was just the turning point of the use of infinitive structure "like to", which has experienced downs and ups and downs again. Twenty years later, that is, in the 1970s, the syntactic structure "would like to" also reached its peak and has been slightly decreasing since then. Of course, in the Sketch Engine query, the grammatical structure "would like to" constitutes a part of "like to".

According to Beeby (2006: 713) grammaticalization involves not only individual lexical items, but also collocations of items, or "conventionalized word sequences". In addition to "would like to", another collocational item "feel like" had been on the rise steadily in terms of its token frequency from the 1810 s to the 1980 s, after which there has been a sharp increase, as indicated in Figure 5.

Based on the schema of the development of auxiliary be going to (Hopper \& Traugott 1993: 61), the grammaticalizaiton of "feel like" can also be schematized as follows:

- $\quad$ Stage I like doing something

- $\quad$ Stage II feel [like doing] something (by reanalysis)

- $\quad$ Stage III [feel like] doing something (by analogy)

During this process, "like" has gradually lost its strong sense meaning "taking pleasure in" or "finding agreeable or congenial"; however, it still has characteristics of the verb "like", since earlier forms may coexist with later ones, and the earlier meaning may constrain later meanings and/or structural characteristics. So "feel like blushing for me" in example (6) means feel shame or embarrassment, and "feel like" in example (7) "to feel like you were seeing recipes" means as if, which has not only deviated from the original meaning, but assumed more grammatical function. What's more, "feel like" in example (6) is used to modify psychological and physiological change of feelings, while "feel like" in example (7) is used to modify a visualized fact. Therefore, on the one hand, the function of the collocation has been bleached; on the other hand, it has crossed different genres with the syntactic changes.

\section{Summary}

The results from query of "like" in BNC with the function of Word Sketch through Sketch Engine show that "like" is very active in terms of both lexical and grammatical functions. Then from the search results in COHA, we have been

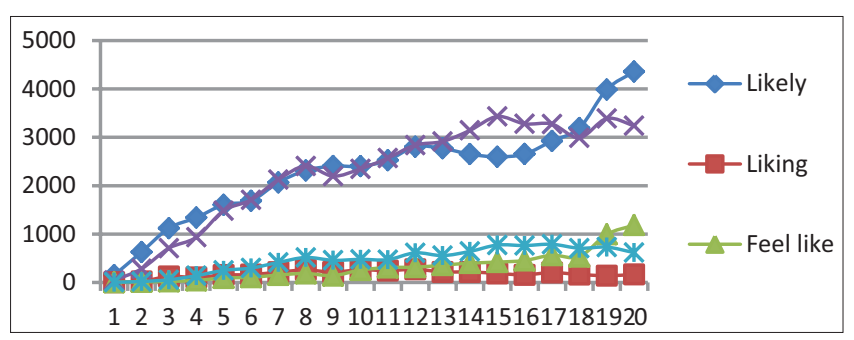

Figure 5. The historical trend of the usage of the variants of "like" in $\mathrm{COHA}$ 
informed that the use of word "like", its variants like "likely" and the collocations such as "like to", "would like to" and "feel like" have been enjoying more and more popularity in English language, though for certain periods in history, the use frequency of one or two of them have experienced ups and downs, yet all indicating the lexical and grammatical changes over time as the result of speakers' preferences for simplicity or pragmatic reasons.

The diachronic evolution of the word "like" is the result of grammaticalization. On the other hand, it has also shown the characteristics of grammaticalization, which is also assumed to be the result of interaction between human beings and languages.

\section{IMPLICATIONS FOR SECOND LANGUAGE PEDAGOGY}

As mentioned above, Chinese L2 learners of English at university level are quite familiar with the word "like" due to its high frequency of exposure; however, when it comes to the practical use especially the combination between syntactic structures and grammatical rules of its variants and collocations, many L2 learners are prone to various errors. One of the causes for these errors is insufficient knowledge of the differences between lexical and grammatical functions. A look back at the process of grammaticalization provides us with the diachronic evolution of the word "like", gradually moving from more lexical to more grammatical along the continuum. For example, the structure "like to $\mathrm{V}$ " that acted as avertive in the mid- $15^{\text {th }}$ century had become obsolete by the end of the $19^{\text {th }}$ century (Kyto \& Romaine 2005; Nicolle 2011). More recently, Diskin (2017) explored the use of "like" as a discourse-pragmatic marker by native and non-native speakers of English in Ireland. Therefore, it is important for the students to bear in mind that, grammar is by no means a "static, closed or self-contained" system, but is subject to change and is easily affected by language use (Bybee 2014:1). The more one uses a language, the more proficient he or she will be. So the instructors should endeavor to design various repetitive exercises to enhance the input of grammatical structures and different collocations so as to consolidate in long-term memory. In this way, the previously independent sequences of units will gradually "be processed as a single unit or chunk" (Bybee 2014:7), thus achieving automatization of production. Yang (2001) concluded from his research on the relationship between grammaticalization and second language pedagogy that, sufficient knowledge of grammaticalization is conducive to the better mastery of preposition collocations and help deepen students' understanding of some errors. The reasons, as revealed by Diessel (2011), lie in the fact that, diachrony and ontogeny involve the same mechanisms of categorization in the process of grammaticalization and language acquisition, resulting in parallel semantic developments.

Furthermore, as corpora are becoming more and more relevant in language teaching (Yepes \& Krishnamurthy 2010), not only can we find out the diachronic evolution of the word "like" through such corpus as COHA, as shown above in this paper, but enable us to access a large number of concordances containing the use of "like" and its variants in BNC. Corpora have undoubtedly provided abundant teaching and learning materials for second language pedagogy, which can help overcome the difficulty of learners in grasping the appropriate use of the word and its collocations through sufficient input and output. For example, when learners are not sure about the grammatical structures following "feel like", the instructors can search the BNC to get a list of authentic examples. What is left to the instructors, is to put the examples into different categories in line with their functions or ask the learners to complete the task first before providing them with the correct answers and explanation.

To sum up, the corpus-based investigation through grammaticalization has revealed both a diachronic evolution of and a synchronic perspective towards the word "like" and its variants. This has not only deepened our understanding but widened our knowledge of the word, its variants and collocations. It is assumed that the approach can be applied to the acquisition of other words, thus promoting second language pedagogy.

\section{REFERENCES}

Bichakjian, B. H. (2017). Language evolution: How language was built and made to evolve. Language Sciences, 63, 119-129. doi:10.1016/j.langsci.2017.03.004.

Bybee, J. (2014). Cognitive processes in grammaticalization. In The new psychology of language (pp. 159-182). Psychology Press.

Diessel, H. (2011).Grammaticalization and language acquisition. In Bernd Heine and Heiko Norrog (eds.), Handbook of Grammaticalization. Oxford: Oxford University Press.

Diskin, C. (2017). The use of the discourse-pragmatic marker "like" by native and non-native speakers of English in Ireland. Journal of Pragmatics, 120, 144-157.

Heine, B. (1997). Possession: Cognitive sources, forces, and grammaticalization. Cambridge: Cambridge University Press.

Heine, B., \& Kuteva, T. (2011). Grammaticalization theory as a tool for reconstructing language evolution. The Oxford Handbook of Language Evolution, eds, 512-527.

Hopper, P. J., \& Traugott, E. C. (1993). grammaticalization. Cambridge: Cambridge University Press.

Junhui Wu, Qingshun He \& Guangwu Feng (2016) Rethinking the Grammaticalization of Future be going to: A Corpus-based Approach, Journal of Quantitative Linguistics, 23:4, 317-341, DOI:10.1080/09296174.2016.1 226427.

Kyto, Merja and Romaine, Suzanne (2005). "“We had like to have been killed by thunder \& lightning": The semantic and pragmatic history of a construction that like to disappeared', Journal of Historical Pragmatics 6: 1-35.

Lehmann, C. (2004). Theory and method in grammaticalization [theorie und methode in der grammatikalisierung]. Zeitschrift Fur Germanistische Linguistik, 32(2), 152-187. doi:10.1515/zfgl.2004.32.2.152.

Meehan, T. (1991). It's like, 'What's happening in the evolution of like?': A theory of grammaticalization. In Ichihashi \& Linn (Eds.). Kansas Working Papers of Linguistics (Volume 16). 
Narrog, H., \& Heine, B. (Eds.). (2011). The Oxford handbook of grammaticalization. Oxford University Press.

Penhallurick, R. J. (2003). Studying the english language. Basingstoke: Palgrave Macmillan.

Pyles, T., \& Algeo, J. (1993). The origins and development of the english language ( $4^{\text {th }}$ ed.). London; Fort Worth;: Harcourt Brace Jovanovich.

Roberts, I. G., \& Roussou, A. (2003). Syntactic change: A minimalist approach to grammaticalization. Cambridge; New York;: Cambridge University Press.

Tagliamonte, S. (2004). Have to, gotta, must: Grammaticalization, variation and specialization in English deontic modality. In Lindquist, H. and Mair, C.(Ed.). Corpus Approaches to Grammaticalization in English: Studies in Corpus Linguistics. Amsterdam/Philadelphia: John Benjamins Publishing Company: 33-55.

Yang, Ch. H. (2001). Research of Grammaticalization and Pedagogy of English as a Foreign Language. Journal of Xi'an Foreign Languages University, Vol. 9, No. 1. pp. $65-68$.

Yepes, G. R., \& Krishnamurthy, R. (2010). Corpus linguistics and second language acquisition-the use of ACORN in the teaching of Spanish Grammar. Lebende Sprachen, 55(1), 108-122. 